\title{
Results from the intercalibration of optical low light calibration sources 2011
}

\author{
B. U. E. Brändström ${ }^{1}$, C.-F. Enell ${ }^{2}$, O. Widell ${ }^{3}$, T. Hansson ${ }^{3}$, D. Whiter ${ }^{4}$, S. Mäkinen ${ }^{4}$, D. Mikhaylova ${ }^{1}$, K. Axelsson ${ }^{1}$, \\ F. Sigernes ${ }^{5}$, N. Gulbrandsen ${ }^{6}$, N. M. Schlatter ${ }^{7}$, A. G. Gjendem ${ }^{8}$, L. Cai ${ }^{9}$, J. P. Reistad ${ }^{10}$, M. Daae ${ }^{8}$, T. D. Demissie ${ }^{8}$, \\ Y. L. Andalsvik ${ }^{11}$, O. Roberts ${ }^{12}$, S. Poluyanov ${ }^{13}$, and S. Chernouss ${ }^{14}$ \\ ${ }^{1}$ Swedish Institute of Space Physics, Kiruna, Sweden \\ ${ }^{2}$ Sodankylä Geophysical Observatory, University of Oulu, Sodankylä, Finland \\ ${ }^{3}$ SSC, ESRANGE, Kiruna, Sweden \\ ${ }^{4}$ Finnish Meteorological Institute, Helsinki, Finland \\ ${ }^{5}$ The Kjell Henriksen Observatory, UNIS, Longyearbyen, Norway \\ ${ }^{6}$ University of Troms $\varnothing$, Troms $\varnothing$, Norway \\ ${ }^{7}$ School of Electrical Engineering, Royal Institute of Technology, Stockholm, Sweden \\ ${ }^{8}$ Norwegian University of Science and Technology, Trondheim, Norway \\ ${ }^{9}$ Department of Physics, University of Oulu, Oulu, Finland \\ ${ }^{10}$ University of Bergen, Bergen, Norway \\ ${ }^{11}$ Department of Physics, University of Oslo, Oslo, Norway \\ ${ }^{12}$ Aberystwyth University, Aberystwyth, UK \\ ${ }^{13}$ Polar Geophysical Institute, Murmansk, Russia \\ ${ }^{14}$ Polar Geophysical Institute, Apatity, Russia \\ Correspondence to: B. U. E. Brändström (urban.brandstrom@irf.se)
}

Received: 5 December 2011 - Published in Geosci. Instrum. Method. Data Syst. Discuss.: 21 December 2011

Revised: 30 March 2012 - Accepted: 11 April 2012 - Published: 3 May 2012

\begin{abstract}
Following the 38th Annual European Meeting on Atmospheric Studies by Optical Methods in Siuntio in Finland, an intercalibration workshop for optical low light calibration sources was held in Sodankylä, Finland. The main purpose of this workshop was to provide a comparable scale for absolute measurements of aurora and airglow. All sources brought to the intercalibration workshop were compared to the Fritz Peak reference source using the Lindau Calibration Photometer built by Wilhelm Barke and Hans Lauche in 1984. The results were compared to several earlier intercalibration workshops. It was found that most sources were fairly stable over time, with errors in the range of 5-25\%. To further validate the results, two sources were also intercalibrated at UNIS, Longyearbyen, Svalbard. Preliminary analysis indicates agreement with the intercalibration in Sodankylä within about $15-25 \%$.
\end{abstract}

\section{Introduction}

Following the first absolute measurement of night airglow by Rayleigh (1930), accurate absolute measurements of airglow and aurora have become increasingly important (see, for example, Trondsen, 1998; Syrjäsuo, 2001; Brändström, 2003; Gustavsson et al., 2006; Dahlgren et al., 2011 and references therein). Such absolute measurements are traditionally expressed in rayleighs, as proposed by Hunten et al. (1956). Further discussions about the definition of the rayleigh unit appear in Chamberlain (1995, App. II) and Baker (1974). In SI units the rayleigh is defined as follows (Baker and Romick, 1976):

$$
1 \text { rayleigh } \equiv 1 \mathrm{R} \triangleq 10^{10} \frac{\text { photons }}{\mathrm{s} \mathrm{m}^{2} \text { column }}
$$

The word column is often inserted in the units above and denotes the concept of an emission rate from a column of unspecified length along the line of sight (Hunten et al., 1956). 
The apparent spectral radiant sterance (spectral radiance), $L_{\gamma}(\lambda)$, can be obtained from the spectral column emission rate, $I(\lambda)$, (in $\mathrm{R} / \AA$ ) ) according to Baker and Romick (1976):

$L_{\gamma}(\lambda)=\frac{10^{10} I(\lambda)}{4 \pi} \frac{\text { photons }}{\mathrm{s} \mathrm{m}^{2} \mathrm{sr} \AA}$.

Integrating the spectral quantities $L_{\gamma}(\lambda)$ and $I(\lambda)$ over wavelength yields the, maybe more familiar, quantities radiance and column emission rate. In this work the rayleigh and the ångström $\left(1 \AA=10^{-10} \mathrm{~m}\right)$ will be used to preserve continuity with earlier intercalibration results, which expressed spectral column emission rate in $\mathrm{R} / \AA$.

After removing the instrument signature (bias, dark current, flat field, bad pixels, etc.), optical instruments are usually absolute calibrated by exposing the instrument to a calibration light source with a known spectral radiant sterance corresponding to a certain column emission rate (see, for example, Trondsen, 1998; Mäkinen, 2001; Brändström, 2003, and references therein). Instead of using calibration light sources, some instruments are calibrated by using known spectra of stars (for example Dahlgren et al., 2011).

This work reports the results of comparisons of calibration light sources during 2011. This is part of a long-term international effort to place aurora and airglow measurements taken at various locations around the world on a common calibration (and hence intensity) standard (Torr and Espy, 1981). In addition, a brief description of the intercalibration method in effect since 1985 is provided.

Following initial efforts in the 1960s by Michael Gadsden (Torr, 1983) and by Torr et al. (1976, 1977), regular intercalibration workshops have been organised (see Table 1 and references therein). After the intercalibration workshop in Katlenburg-Lindau in 1983, Lauche and Barke (1986) constructed the Lindau Calibration Photometer for comparison of low brightness sources (Fig. 1). This was done in order to support the work by $\mathrm{M}$. Torr in the European sector. Yet, calibration sources from other countries have participated in some workshops over the years. As seen in Table 1 , some intercalibration workshops have also taken place in non-European countries.

When Hans Lauche retired, Widell and Henricson (2003) took over the responsibility for the Lindau Calibration Photometer, and following Ola Widell's retirement in 2011, this responsibility was handed over to the corresponding author of this paper. Table 1 is an attempt to list all known official intercalibration workshops to date.

\section{Calibration sources}

In this calibration effort nine calibration sources were compared to the Fritz Peak (FP) reference source (this source is labelled "Fritz Peak international standard source"). This radioactive ${ }^{14} \mathrm{C}$-activated phosphor source is only used at intercalibration workshops. Apart from the FP reference source,
Table 1. Known official intercalibration workshops. The 1967 1972 intercalibrations are mentioned by Torr (1983). Regarding later calibration workshops lacking a literature reference, the results and raw data are archived by the corresponding author of this paper. Copies are available upon request. The column \# refers to the number of participating calibration sources.

\begin{tabular}{lrll}
\hline Year & $\#$ & Location & Reference/responsible \\
\hline 1967 & & Fritz Peak & Gadsden and Marovich \\
1968 & & Paris & Weill \\
1969 & & Tokyo & Huruhata \\
1970 & & Kitt Peak & Broadfoot \\
1970 & & Harvard & Noxon \\
1970 & & Johns Hopkins & Schaeffer and Fastie \\
1972 & & Lindau & Leinert and Klüppelberg \\
1979 & 9 & Seattle & Torr (1981) \\
1981 & 30 & Aberdeen & Torr and Espy (1981) \\
1983 & 21 & Lindau & Lauche \\
1985 & 16 & Lysebu & Lauche and Barke (1986) \\
1987 & 14 & Saskatoon & Lauche \\
1989 & 1 & Lindau & Lauche \\
1991 & 6 & Wien & Lauche (IAGA) \\
1995 & 4 & Boulder & Lauche \\
1999 & 18 & Lindau & Lauche and Widell (2000b) \\
2000 & 9 & Stockholm & Lauche and Widell (2000a) \\
2001 & 10 & Oulu & Widell and Henricson (2003) \\
2003 & 8 & Longyearbyen & Widell and Mämmi (2003) \\
2006 & 7 & Kiruna & Widell and Henricson (2008) \\
2007 & 6 & Andøya & Henricson (2008) \\
$2011 \mathrm{a}$ & 10 & Kiruna & This work \\
$2011 \mathrm{~b}$ & 10 & Sodankylä & This work \\
$2011 \mathrm{c}$ & 3 & Longyearbyen & This work (prel. results) \\
\hline & & &
\end{tabular}

the IRF UJO 920B, L1614, Y275 and the MPI-2 sources are also radioactive ${ }^{14} \mathrm{C}$ activated phosphor sources. The spectral output is continuous and depends on the phosphor. The IRF UJO sources are "light standards", probably manufactured by U.S. Radium Corp. in the 1960s and labelled with phosphor type and luminance values, "920B $<20 \mu \mathrm{L}$ ", "L1614 $7 \mu \mathrm{L} \pm 10 \% "$ and "Y275 $15 \mu \mathrm{L} \pm 10 \% "$, respectively. The lambert $\mathrm{L}$ is a non-SI unit of luminance; $1 \mathrm{~L}$ corresponds to $10^{4} / \pi \mathrm{cd} \mathrm{m}^{-2}$. It is furthermore a photometric unit, involving the spectral sensitivity of the human eye. These luminance values have probably never been used for calibration purposes, at least not in recent years.

Several of these sources have participated in intercalibrations dating back to the late 1960s (see Torr, 1983, Fig. 1). Although stable and easy to handle, these sources are nowadays rather difficult to transport due to flight safety regulations.

The ESRANGE tungsten lamp and the IRF Lauche lamp are tungsten lamps that operated at a predefined lamp current. Both were designed by Hans Lauche. The ESRANGE tungsten lamp was powered by an external power supply, while the IRF Lauche lamp has its own constant current supply. 


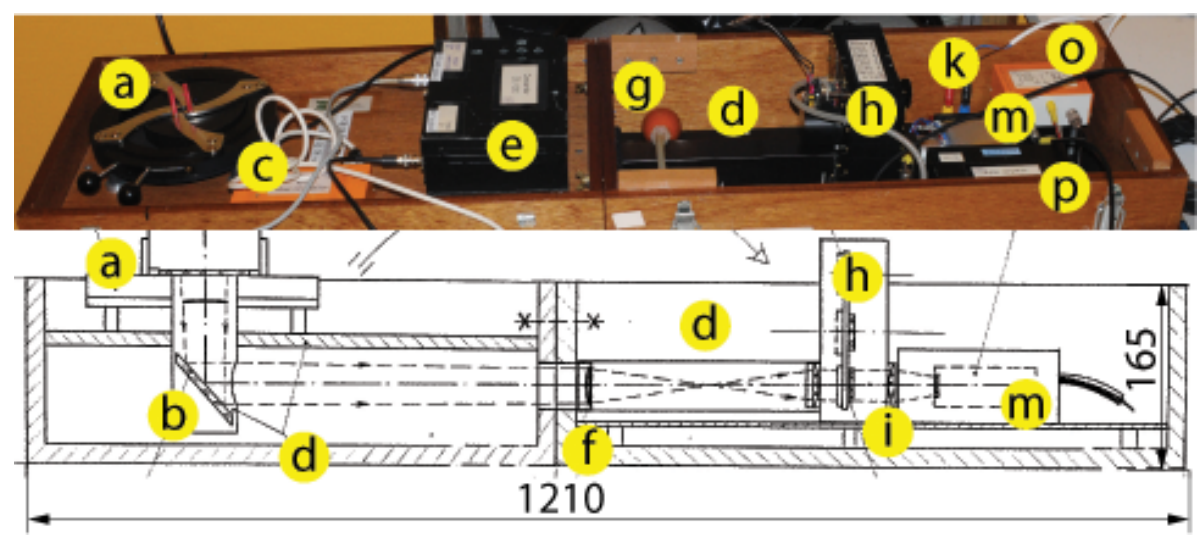

Fig. 1. The Lindau Calibration Photometer built by W. Barke and Hans Lauche at Max Planck Institute for Aeronomy, Katlenburg-Lindau (1984). (a) centering device for source under measurement (b) deflecting mirror, (c) power supply for pulse amplifier, (d) collimators, (e) HV supply. (f) objective lens, (g) dehumidifier, (h) filter wheel, (i) field stop, (k) Peltier cooler connector, (m) PMT Hamamatsu R-632, (o) connection box and (p) pulse amplifier.

These sources are not considered as stable as the radioactive sources, but on the other hand, they are much easier to transport.

The stability of the radioactive sources and the IRF Lauche lamp is discussed in Sect. 6.

Two sources are based on light-emitting diodes (LEDs): the ESRANGE MSP1 and the PGI Chernouss-38AM. The ESRANGE MSP1 has internal current regulators and is powered by a $28 \mathrm{~V}$ supply, while the PGI Chernouss-38AM is battery powered. Both participating LED sources consist of several LEDs and none of them has participated in earlier intercalibration workshops.

The FMI sphere (Mäkinen, 2001) consists of an integrating sphere, three identical $30 \mathrm{~W}$ internal tungsten lamps, a $75 \mathrm{~W}$ external tungsten lamp with a mechanical attenuator and several neutral density (ND) filters. The ND filters are required to decrease the output of the sphere to acceptable levels for low light instrumentation. The output of the sphere is calibrated by the manufacturer in foot-lamberts (an American customary unit for luminance; $1 \mathrm{ft}-\mathrm{L}$ corresponds to $3.426 \mathrm{~cd} \mathrm{~m}^{-2}$ ). Note that this is a photometric unit involving the spectral sensitivity of the human eye, and that this calibrated luminance value is valid at the exit aperture of the integrating sphere, i.e. before the ND filters. Thus, for the intercalibrating effort described here, the luminance value should only be regarded as a source setting. However, knowing the spectral response of the ND filters, it is possible to compare the calibrated output of the sphere to the results presented in this report. It is hoped that this will be done in the future.

It should be noted that the ESRANGE sources were intercalibrated on 16 September 2011 at the Swedish Institute of Space Physics in Kiruna (referred to as 2011a), while all other sources except the FMI sphere were intercalibrated on 19 October 2011, at Sodankylä Geophysical Observatory in Sodankylä, Finland. The FMI sphere was intercalibrated on the same date at the calibration laboratory at Finnish Meteorological Institute's Arctic Research Centre (FMI-ARC), also in Sodankylä. Both Sodankylä intercalibrations above are referred to as 2011b. The IRF sources as well as the MPI-2 source were intercalibrated at both locations.

During the course "Optical methods in auroral physics research" held in November 2011 at the University Centre in Svalbard (UNIS), the IRF Lauche lamp and the PGI Chernouss-38AM sources were intercalibrated with an SN1633 NIST-traceable tungsten lamp in the calibration laboratory at UNIS (Sigernes et al., 2007). This intercalibration is referred to as $2011 \mathrm{c}$.

During earlier intercalibration workshops the source naming conventions have been somewhat different for some sources. To remedy this in the future, a unique source identification number (SID) was introduced in 2011 to simplify future comparisons. Radioactive calibration sources have been assigned SID in the range 1-99; other sources are numbered from 101 (see Table 2).

This report only concerns sources intercalibrated in 2011. A full list of all sources that participated in this long-term calibration series is under preparation. Some of the participating calibration sources are shown in Fig. 2.

\section{The Lindau Calibration Photometer}

The Lindau Calibration Photometer is described by Lauche and Barke (1986). Furthermore, all technical documentation and design drawings, raw data and results from the calibration photometer as well as previous intercalibration workshops are archived by the corresponding author of this paper and are available upon request. As soon as time permits, this information will be scanned and made available on the Internet. 
Table 2. Results of the intercalibration workshop. All values are spectral column emission rates in R/Å. The absolute calibration values at $3914 \AA$ should be considered less reliable (see Sect. 6). Filter transmittance plots are available upon request. SID is source identification number.

\begin{tabular}{|c|c|c|c|c|c|c|c|c|c|c|}
\hline Filter position & & 1 & 2 & 3 & 4 & 5 & 6 & 7 & & \\
\hline Filter CW & & 3914 & 4280 & 4866 & 5573 & 5882 & 6299 & 6562 & {$[\AA]$} & \\
\hline Filter bandwidth (FWHM) & & 41 & 27 & 25 & 16 & 13 & 12 & 15 & {$[\AA]$} & \\
\hline Source name & SID & & & & & & & & Settings & Note \\
\hline FP reference source & 1 & 0.34 & 5.7 & 3.2 & 2.6 & 5.1 & 9.2 & 15 & Torr and Espy (1981) & \\
\hline MPI-2 & 2 & & & 2 & 173 & 263 & 187 & 93 & ${ }^{14} \mathrm{C}$ & \\
\hline IRF UJO 920B & 3 & 4 & 101 & 62 & 22 & 13 & 8 & 4 & ${ }^{14} \mathrm{C}$ Phosphor 920B & \\
\hline IRF UJO L1614 & 4 & 5 & 1 & 38 & 34 & 9 & & & ${ }^{14}$ C Phosphor L1614 & \\
\hline IRF UJO Y275 & 5 & & & 4 & 261 & 362 & 201 & 107 & ${ }^{14} \mathrm{C}$ Phosphor Y275 & \\
\hline IRF Lauche lamp & 101 & & 1 & 8 & 54 & 96 & 207 & 352 & $1.62 \mathrm{~V}, 198.50 \mathrm{~mA}$ & 1 \\
\hline IRF Lycksele lamp & 102 & & 1 & 9 & 72 & 150 & 360 & 489 & $6.21 \mathrm{~V}, 22.7 \mathrm{~mA}$ & 2 \\
\hline ESRANGE tungsten lamp & 103 & 3 & 10 & 61 & 359 & 544 & 728 & 635 & $10.9 \mathrm{~V}, 217.5 \mathrm{~mA}$ & 2,3 \\
\hline ESRANGE tungsten lamp & 103 & & & 1 & 6 & 12 & 20 & 32 & $5.10 \mathrm{~V} 141.00 \mathrm{~mA}$ & 2,3 \\
\hline ESRANGE MSP1 & 104 & 226 & 335 & 150 & 280 & 308 & 523 & 299 & LED 28 V supply & 1,3 \\
\hline PGI Chernouss-38AM & 105 & 12 & 164 & 382 & 710 & 639 & 1520 & 1782 & LED, setting $3(\max )$ & 4 \\
\hline FMI sphere & 106 & & 5 & 26 & 72 & 78 & 180 & 353 & $\mathrm{~L}: \mathrm{C}, \mathrm{A}: 150, \mathrm{ND}: 7,1473.3 \mathrm{ft}-\mathrm{L}$ & 5 \\
\hline FMI sphere & 106 & & 9 & 49 & 139 & 150 & 348 & 696 & $\mathrm{~L}: \mathrm{C}, \mathrm{A}: 255, \mathrm{ND}: 7,3092.0 \mathrm{ft}-\mathrm{L}$ & 5 \\
\hline FMI sphere & 106 & 1 & 13 & 67 & 170 & 189 & 422 & 809 & $\mathrm{~L}: \mathrm{BC}, \mathrm{A}: 100, \mathrm{ND}: 7,3388.0 \mathrm{ft}-\mathrm{L}$ & 5 \\
\hline FMI sphere & 106 & 1 & 20 & 100 & 294 & 304 & 682 & 1311 & $\mathrm{~L}: \mathrm{BC}, \mathrm{A}: 255, \mathrm{ND}: 7,5947.0 \mathrm{ft}-\mathrm{L}$ & 5 \\
\hline
\end{tabular}

Notes: 1. Constant current supply, 2. adjustable power supply, 3. 2011a intercalibration (Kiruna 16 September), 4. battery powered, 5. settings refer to lamp(s) in use (L), attenuator setting (A), neutral density filter (ND) and luminance in foot-lamberts (before the neutral density filters).

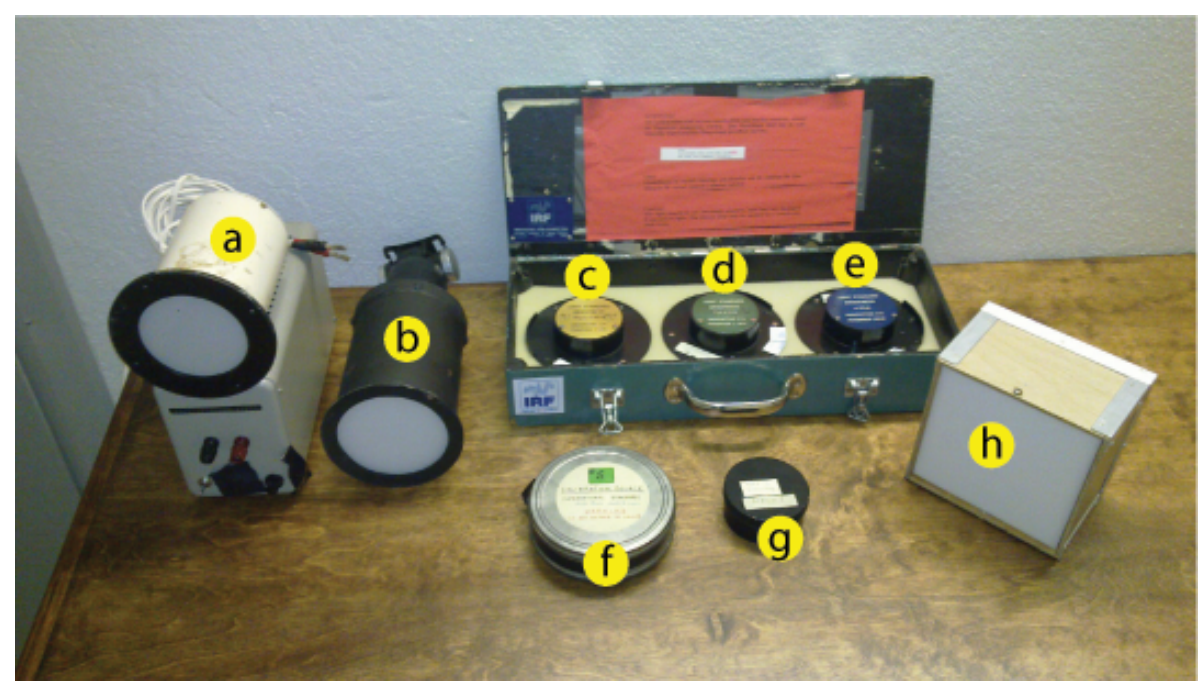

Fig. 2. Some of the low light sources intercalibrated at this workshop: (a) IRF Lauche lamp (SID 101) with power supply, (b) PGI Chernouss38AM (SID 105), (c) IRF UJO Y275 (SID 5), (d) IRF UJO L1614 (SID 4), (e) IRF UJO 920B (SID 3), (f) FP reference source (SID 1), (g) MPI-2 source (SID 2) and (h) IRF Lycksele lamp (SID 102).

Figure 1 shows the general layout of the instrument. The source is attached to the centering device (a) and light passes a mirror (b), collimating tubes (d), an objective lens (f), filter wheel (h), with telecentric optics and field stop (i) and finally reaches the Peltier-cooled photomultiplier tube (PMT, Hamamatsu R632 GA37). Datasheets with plots of spectral response and quantum efficiency for this
PMT are available on the Internet (www.datasheetcatalog. org/datasheet/hamamatsu/R632.pdf). The length of the instrument is $1210 \mathrm{~mm}$, and the height is $165 \mathrm{~mm}$. The two parts are folded together during transportation. 


\section{Intercalibration procedure}

The Lindau Calibration Photometer was installed in a darkroom and the Peltier cooler was switched on several hours before measurements, so that the photomultiplier tube (PMT) would be sufficiently cooled and thermally stable. One person operated the calibration photometer and sources in the darkroom, while another person recorded the filter position and PMT counts using a filter position display and a precision frequency counter (HP 5328A and HP 53181A for 2011a and $2011 \mathrm{~b}$, respectively) located outside the darkroom. The frequency counter was set for a long gate time (3-5s). In addition, an intercom was available between the darkroom and the outside. Filter position 0 is blocked and corresponds to dark current; the remaining positions correspond to seven filters from 3914 to $6562 \AA$ (listed in Table 2). The filter bandwidths in the table correspond to the full width at half maximum (FWHM). Position 8 corresponds to a filter with centre wavelength $6707 \AA$. This filter is included in the intercalibration procedure, but the results are traditionally discarded since the FP reference source lacks calibration data for this wavelength. Transmittance curves for each filter exist in the calibration photometer documentation and are available upon request. Each source was then compared to the FP reference source. This was done according to the following procedure:

1. The FP reference source was attached to the centering device of the calibration photometer (Fig. 1a).

2. Three measurements were recorded from the frequency counter for each of the nine filter wheel positions (including dark current). As the filter wheel was rotated manually, the filter changes were announced and verified over the intercom and by using the filter position display.

3. The FP reference source was then replaced with the calibration source and step 2 above was repeated for that source. Metadata was recorded (filter temperature, start and stop times, etc.).

4. Steps 1-3 above were repeated for each of the nine calibration sources.

The spectral column emission rate $\left(I_{\mathrm{Sp}}\right)$ at filter position $p$ (1..8) was then calculated from the following equation (by using a spreadsheet):

$I_{\mathrm{Sp}}=\frac{I_{\mathrm{Rp}}\left(\bar{S}_{p}-\bar{S}_{0}\right)}{\bar{R}_{p}-\bar{R}_{0}} \frac{\mathrm{R}}{\AA}$

where $\bar{S}_{p}$ and $\bar{R}_{p}$ are the average measured count rates for the calibration source and the FP reference source, respectively; $\bar{S}_{0}$ and $\bar{R}_{0}$ are averaged dark current measurements (filter position 0 ). $I_{\mathrm{Rp}}$ is the FP reference spectral column emission rate for filter $p$ (refer to Table 2). To preserve continuity this procedure has been changed as little as possible since 1985 .

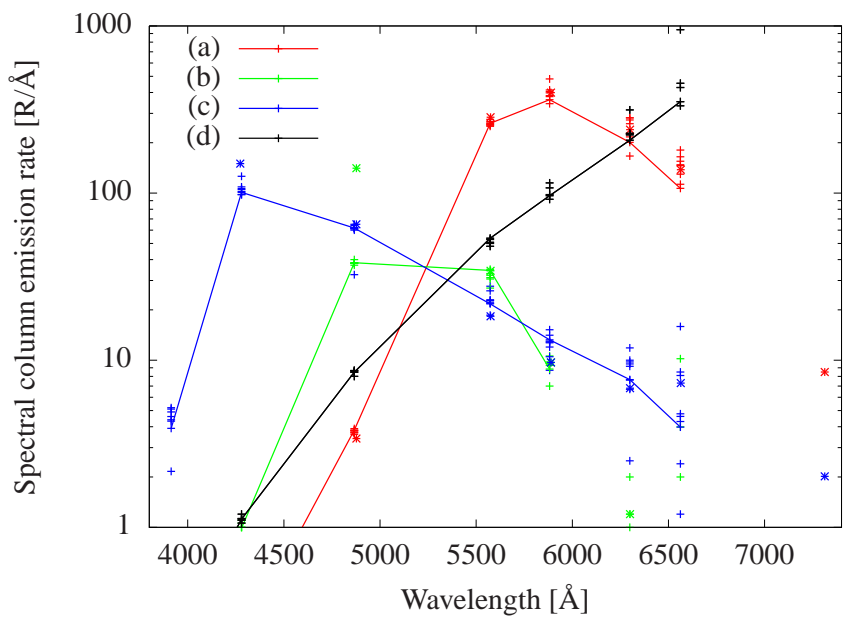

Fig. 3. Intercalibration results for three sources since 1981: (a) IRF UJO Y275 (SID 5), (b) IRF UJO L1614 (SID 4), (c) IRF UJO 920B (SID 3), (d) IRF Lauche lamp (SID 101, since 2000). The 2011b intercalibration results are connected with lines, giving a rough idea of the spectra of these sources. The 1981 intercalibration used different filters indicated by a "**".

\section{Results}

The results from this intercalibration effort are given in Table 2. Note that spectral column emission rates less than $1 \mathrm{R} / \AA$ have been removed in Table 2 due to poor signal-tonoise ratio. All raw data and preliminary results before postprocessing are available at http://alis.irf.se/ewoc/2011.

Figure 3 plots all intercalibration results from 1981 until the present time for three radioactive and one tungsten lamp source. Table 3 lists the ratios of this intercalibration to earlier intercalibration workshops, as well as to the mean value of all listed workshops. Sources not appearing in Table 3 have only been intercalibrated once, or earlier intercalibration data have not been located yet. Figure 4 plots selected ratios from Table 3 as a time series. The ratios and wavelengths are selected based on the normal usage of the source for calibration of optical instrumentation.

The intercalibration was done under two assumptions: (1) the spectral radiant sterance of the FP reference source is stable and sufficiently well known, and (2) the calibration photometer is linear and stable during the calibration.

\section{Discussion}

The FP reference source is traceable to intercalibrations in the late 1960s (Torr, 1983) and the present absolute calibration values, obtained with a national standard source (Q47 tungsten filament lamp, calibrated by the National Bureau of Standards in 1977) from an intercalibration done by Torr and Espy (1981). Since 1981 the FP reference source has been used as reference source for intercalibration workshops in the 
Table 3. Ratios of the 2011 b intercalibration (Sodankylä) to earlier intercalibrations and to the mean value of all listed measurements. Sources not appearing in this table lack information of earlier calibration workshops. SID is source identification number.

\begin{tabular}{|c|c|c|c|c|c|c|c|c|c|}
\hline \multirow[b]{2}{*}{ Source name } & \multirow[b]{2}{*}{ SID } & \multirow[b]{2}{*}{ Year } & \multicolumn{7}{|c|}{ Filter $[\AA]$} \\
\hline & & & 3914 & 4280 & 4866 & 5573 & 5882 & 6299 & 6562 \\
\hline \multirow[t]{9}{*}{ IRF UJO 920B } & 3 & 1981 & & 0.67 & 0.95 & 1.19 & 1.36 & 1.12 & 0.55 \\
\hline & & 1985 & 0.77 & 0.80 & 1.01 & 1.17 & 1.26 & 1.14 & 0.49 \\
\hline & & 1999 & 0.89 & 0.99 & 1.03 & 0.99 & 1.10 & 1.01 & 1.66 \\
\hline & & 2000 & 0.85 & 0.93 & 0.97 & 0.95 & 1.04 & 0.77 & 0.47 \\
\hline & & 2001 & 0.75 & 0.96 & 0.95 & 0.99 & 1.02 & 0.83 & 3.32 \\
\hline & & 2006 & 0.80 & 0.95 & 1.00 & 0.95 & 0.94 & 0.81 & 0.25 \\
\hline & & 2007 & 0.91 & 1.03 & 1.01 & 0.96 & 0.87 & 0.65 & 0.86 \\
\hline & & $2011 \mathrm{a}$ & 1.81 & 1.03 & 0.99 & 0.84 & 1.03 & 0.78 & 0.83 \\
\hline & & Mean & 1.02 & 0.91 & 0.99 & 0.99 & 1.05 & 0.87 & 0.63 \\
\hline \multirow{9}{*}{ IRF UJO L1614 } & 4 & 1981 & & 1.24 & 0.27 & 1.00 & 0.91 & & 2.20 \\
\hline & & 1985 & 1.14 & 1.36 & 1.18 & 1.24 & 1.02 & & 0.23 \\
\hline & & 1999 & 0.13 & 0.99 & 1.04 & 1.04 & 0.95 & & 0.49 \\
\hline & & 2000 & 1.14 & 0.99 & 0.96 & 0.98 & 0.92 & & 1.74 \\
\hline & & 2001 & 0.80 & 0.90 & 1.01 & 1.28 & 1.26 & & 0.10 \\
\hline & & 2006 & 0.57 & 0.93 & 1.00 & 1.10 & 0.83 & & 0.25 \\
\hline & & 2007 & 1.33 & 0.99 & 1.01 & 1.07 & 0.91 & & \\
\hline & & $2011 \mathrm{a}$ & 0.80 & 1.03 & 1.01 & 1.13 & 0.93 & & \\
\hline & & Mean & 0.59 & 1.03 & 0.78 & 1.09 & 0.96 & & 0.52 \\
\hline \multirow{9}{*}{ IRF UJO Y275 } & 5 & 1981 & & 6.00 & 1.12 & 0.92 & 0.91 & 0.84 & 0.77 \\
\hline & & 1985 & 0.33 & 0.70 & 1.01 & 1.04 & 0.96 & 0.93 & 0.94 \\
\hline & & 1999 & 1.00 & 1.05 & 1.01 & 0.99 & 0.94 & 0.71 & 0.65 \\
\hline & & 2000 & 1.00 & 0.95 & 0.98 & 0.95 & 0.89 & 0.71 & 0.59 \\
\hline & & 2001 & 5.00 & 1.17 & 1.06 & 1.01 & 0.75 & 0.73 & 0.69 \\
\hline & & 2006 & & 0.91 & 1.03 & 1.03 & 0.91 & 0.89 & 0.72 \\
\hline & & 2007 & 1.00 & 1.11 & 1.04 & 1.02 & 0.87 & 0.77 & 0.82 \\
\hline & & $2011 \mathrm{a}$ & 0.33 & 1.00 & 1.03 & 0.98 & 1.06 & 1.21 & 0.73 \\
\hline & & Mean & 0.88 & 1.06 & 1.03 & 0.99 & 0.91 & 0.84 & 0.75 \\
\hline \multirow[t]{5}{*}{ IRF Lauche lamp } & 101 & 2000 & 0.95 & 1.02 & 1.00 & 1.07 & 0.98 & 0.93 & 0.78 \\
\hline & & 2001 & 1.06 & 0.93 & 1.06 & 1.12 & 0.84 & 0.91 & 0.82 \\
\hline & & 2007 & 1.20 & 1.06 & 0.98 & 1.06 & 0.90 & 0.92 & 1.06 \\
\hline & & $2011 \mathrm{a}$ & 1.06 & 0.99 & 0.98 & 1.02 & 1.05 & 0.66 & 0.37 \\
\hline & & Mean & 1.05 & 1.00 & 1.00 & 1.05 & 0.95 & 0.86 & 0.70 \\
\hline
\end{tabular}

aurora/airglow optical community. Note that the 1981 calibration did not include $3914 \AA$ and $6707 \AA$. The origin of the absolute calibration value at $3914 \AA(0.34 \mathrm{R} / \AA)$ is currently unknown. This is under investigation, and until further notice it should be treated as less reliable (extrapolated). As 1981 is a rather long time ago, doubts can clearly be cast on the stability of the FP reference source. It is thus of great importance to compare the FP reference source to a source traceable to a National Bureau of Standards as soon as possible. Although strongly desired, this has not been possible yet. Some steps have therefore been taken to indirectly assess the stability of the FP reference source.

Preliminary results from the independent 2011c intercalibration (Longyearbyen) of two sources are given in Table 4.
In addition, the spectra of these two sources were measured with a spectrograph. For the IRF Lauche source (SID 101), deviations appear to be less than $\pm 15 \%$ for wavelengths from $5573 \AA$. For shorter wavelengths this source has a very low output, as should be expected from a tungsten lamp. The ratios for the PGI Chernouss-38AM (SID 105) source are a bit more puzzling and, in particular, the large difference for $4866 \AA$ is still under investigation. The spectrum of the PGI Chernouss-38AM LED source was found to be continuous but with two sharp peaks. One possible preliminary explanation for the discrepancy is that while the former calibrations were done by a filtered photometer, the 2011c calibration was done with a spectrograph. The spectrograph had a bandpass of approximately $100 \AA$, while the photometer filters have 

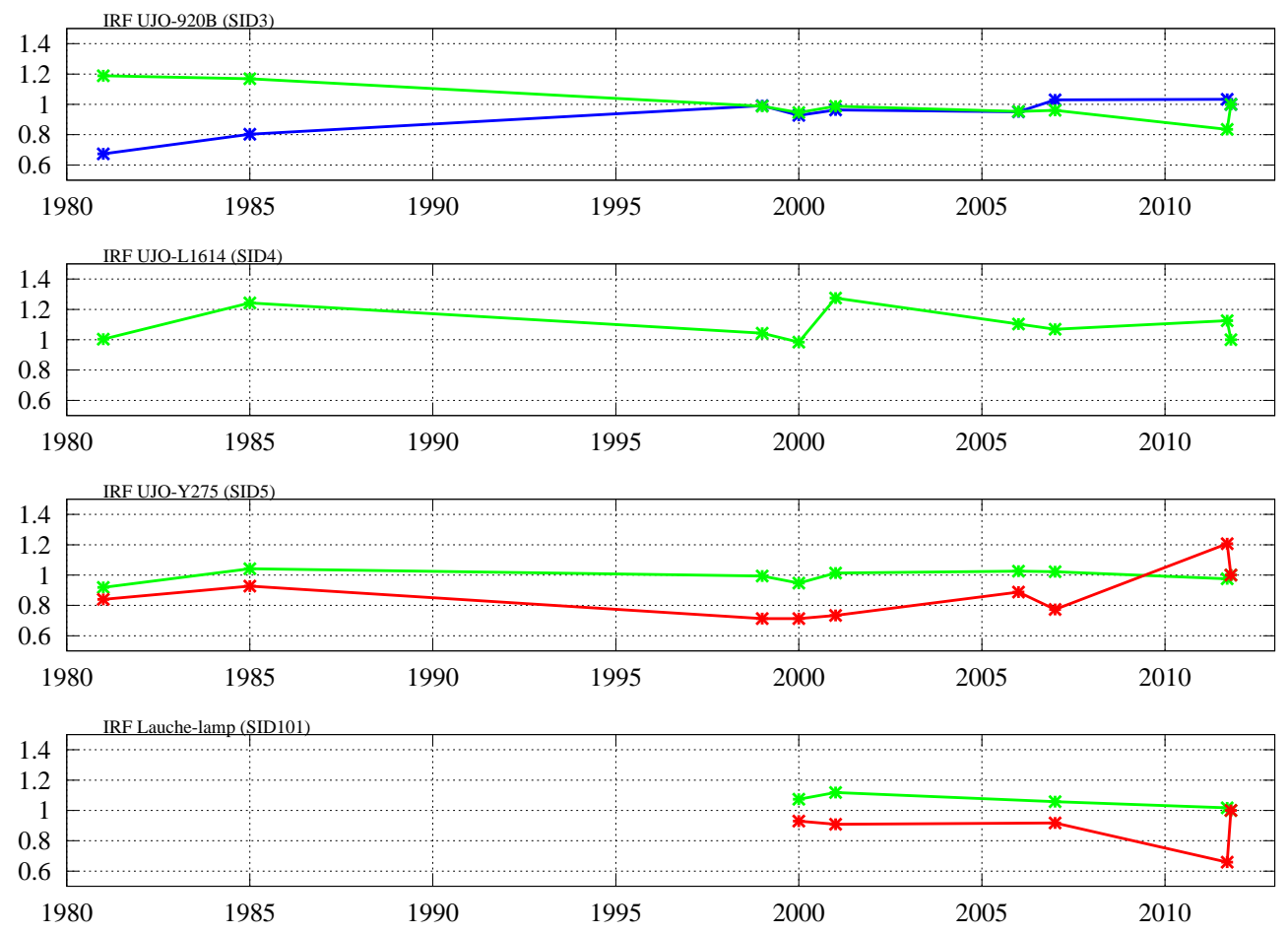

Fig. 4. Ratios of 2011b intercalibration in Sodankylä to earlier intercalibrations for IRF UJO 920B (SID3, top panel), IRF UJO L1614 (SID 4), IRF UJO Y275 (SID5) and IRF Lauche lamp (SID101) (bottom panel): (blue) $4280 \AA$, (green) $5573 \AA$ and (red) $6299 \AA$. Note that none of these sources were intercalibrated 1987-1995.

a bandpass around $20 \AA$. As this source has no earlier intercalibration history, additional measurements are required. A preliminary conclusion from the $2011 \mathrm{c}$ intercalibration is that the intercalibration error for the FP reference source is probably less than $\pm 25 \%$ for wavelengths from $5573 \AA$. This preliminary, but promising, conclusion is to be confirmed by the final results from the $2011 \mathrm{c}$ intercalibration session.

The FMI MIRACLE EMCCD imager normally operated at Kilpisjärvi was recently calibrated by the manufacturer, Keo Scientific in Canada (T. S. Trondsen, personal communication, 2011). For further validation, this imager was then calibrated by the FMI integrating sphere and two of the IRF radioactive sources (920B and Y275). Data from this effort are not analysed yet and will appear in a later publication. Then, it will be possible to compare the $2011 \mathrm{~b}$ intercalibration both to the calibration by Keo Scientific in Canada as well as to the FMI integrating sphere.

Furthermore, if the FP reference source should become unstable over time, it is highly likely that other ${ }^{14} \mathrm{C}$-activated phosphor sources also would become unstable. This would be noticed as increasing deviations between the intercalibration workshops.

It has been found that Torr and Espy (1981) and Lauche and Barke (1986) did not use exactly the same filter sets. This is under investigation and might explain the difference in ratios for 1981 and 1985 (Fig. 4).
The 2011a intercalibration was mainly a practice run by a new calibration team before the official $2011 \mathrm{~b}$ intercalibration in Sodankylä. This might explain the larger deviations seen for the 2011a intercalibration (Table 3 and Fig. 4). The 2011a intercalibration should therefore be excluded from the long-term series, if results from later workshops confirm it to be an outlier.

Aging effects of various components (sources, filters, PMT, etc.) will also contribute to the errors. Looking at Fig. 3 it is seen that the intercalibration errors tend to increase towards the red part of the spectra. This is under investigation and is probably related either to aging effects (PMT and/or filters), stray light, or to design compromises of the calibration photometer.

On the other hand, the IRF UJO Y275 (SID 5) source appears very stable over time at $5573 \AA$ (Fig. 4). In fact, recovered fragments of old documentation (1960s) concerning "light calibration by $\mathrm{C} 14$ activated light standards from U.S. Radium Corp." appear to indicate $262.65 \mathrm{R} / \AA$ for the IRF UJO Y275 (SID 5) at $5600 \AA$ (by conversion of the luminance values stamped onto the source; see Sect. 2). This is to be compared to the $2011 \mathrm{~b}$ intercalibration that gave $261 \mathrm{R} / \AA$ at $5573 \AA$. To confirm this, the spectra of these sources must be measured. It is hoped that this will be possible in the autumn of 2012.

The mean ratios in Table 3 indicate a typical deviation, ranging from a few percent to around $\pm 10 \%$ for wavelengths 
Table 4. Preliminary ratios of this intercalibration to measurements in November 2011 at the calibration laboratory at UNIS, Longyearbyen, Svalbard (2011c). The large differences for wavelengths below $5573 \AA$ are expected since the IRF Lauche lamp is a tungsten lamp. For the PGI Chernouss-38AM source, the large difference at $4866 \AA$ is more puzzling and remains to be explained.

\begin{tabular}{lcccccccc}
\hline & & \multicolumn{7}{c}{ Filter $[\AA]$} \\
\cline { 3 - 9 } Source name & SID & 3914 & 4280 & 4866 & 5573 & 5882 & 6299 & 6562 \\
\hline IRF Lauche lamp & 101 & 0.02 & 0.10 & 0.32 & 0.85 & 0.89 & 0.96 & 1.11 \\
PGI Chernouss-38AM & 105 & 0.53 & 0.86 & 0.30 & 0.69 & 0.75 & 0.95 & 1.09 \\
\hline
\end{tabular}

$4280,4866,5573$ and $5882 \AA$. For $6299 \AA$ this value is around $\pm 15 \%$.

While none of what is said above provides hard evidence concerning the validity of the 30-year-old absolute calibration of the FP reference source, it is probably safe to assume that absolute calibration errors are probably less than 15-25\%, with a few exceptions and not including filters at 3914 and $6707 \AA$. This is also in agreement with Torr and Espy (1981), who report an accuracy of $\pm 10 \%$ over a 12 year-period. This should be compared to differences up to a factor of six during the early phases of this long-term intercalibration effort (Torr et al., 1977). Finally, even in the case that the absolute calibration values are completely wrong, the relative intercalibration is not affected by this, and thus it would be possible to correct these errors in the future.

\section{Conclusions}

This work presents the official results from the intercalibration workshop following the 38th Annual European Meeting on Atmospheric Studies by Optical Methods (in Table 2). Ratios of this intercalibration to earlier work are presented in Table 3 and Fig. 4. Preliminary results of the independent 2011c intercalibration (Longyearbyen) of two sources are given in Table 4.

A brief description of the intercalibration method, in effect since 1985, is provided. Furthermore, a large set of documentation and publications regarding this long-term intercalibration effort has been collected. As much as possible of this information will be made available on the Internet (http://alis.irf.se/ewoc/).

It is concluded that well-justified doubts exist about the validity of the absolute calibration of the FP reference source after 30 years. On the other hand, preliminary results from the 2011c intercalibration (Table 4) suggest errors of around $\pm 15 \%$ for wavelengths from $5573 \AA$ and possibly also at $4280 \AA$. This is to be confirmed by the final results of the 2011c intercalibration as well as to be compared to the calibrations of the FMI MIRACLE EMCCD, performed in Canada by Keo Scientific and to the certified luminance values of the FMI sphere. Until this is done the absolute calibration error is estimated at $15-25 \%$ and the relative intercalibration error at 5-25\%.

\section{Future work}

Following the intercalibration efforts in 2011, several radioactive calibration light sources have been found in Norway (Y. L. Andalsvik, personal communication, 2012). Many of these sources appear in earlier intercalibration workshops, in particular at the Lysebu 1985 workshop (Lauche and Barke, 1986). In addition, at least two calibration sources have been found at University of Oulu, Finland. Therefore, it would be desirable to include these sources in the intercalibration workshop planned for the autumn of 2012 in Sodankylä.

For the next workshop it will hopefully also be possible to measure the spectra of all participating sources. This is of general importance for improving the quality of this longterm intercalibration effort, but, in particular, it might help resolve problems related to LED-based sources, such as the PGI Chernouss-38AM source (SID 105).

This intercalibration effort should also be compared to absolute calibration methods involving the known spectra of stars.

The intercalibration procedure from 1985 is a rather tedious and manual nature. To automate the filter wheel operation and data acquisition would probably both improve the accuracy and speed up the intercalibration procedure.

Last but not least, it is of the utmost importance to perform an intercalibration of the FP reference source to a source traceable to a National Bureau of Standards source as soon as possible.

Acknowledgements. This work is presented in memory of Ingrid Sandahl who passed away in 2011. This work was funded by a University of Oulu grant for short-term international research visits. The comparison at UNIS was financed by a grant from the Nordic Council of Ministers. The authors also wish to thank two anonymous referees for their unusually helpful and thorough review of this work.

Edited by: A. Benedetto 


\section{References}

Baker, D. J.: Rayleigh, the Unit for Light Radiance, Appl. Optics, 13, 2160-2163, 1974.

Baker, D. J. and Romick, G. J.: The Rayleigh: interpretation of the unit in terms of column emission rate or apparent radiance expressed in SI units, Appl. Optics, 15, 1966-1968, 1976.

Brändström, U.: The Auroral Large Imaging System - Design, operation and scientific results, Ph.D. thesis, Swedish Institute of Space Physics, Kiruna, Sweden, (IRF Scientific Report 279), ISBN: 91-7305-405-4, 2003.

Chamberlain, J. W.: Physics of the aurora and airglow, Classics in geophysics, AGU (American Geophysical Union), (A reprint of the original work from 1961), 1995.

Dahlgren, H., Gustavsson, B., Lanchester, B. S., Ivchenko, N., Brändström, U., Whiter, D. K., Sergienko, T., Sandahl, I., and Marklund, G.: Energy and flux variations across thin auroral arcs, Ann. Geophys., 29, 1699-1712, doi:10.5194/angeo-291699-2011, 2011.

Gustavsson, B., Leyser, T. B., Kosch, M., Rietveld, M. T., Åke Steen, Brändström, B. U. E., and Aso, T.: Electron Gyroharmonic Effects in Ionization and Electron Acceleration during High-Frequency Pumping in the Ionosphere, Phys. Rev. Lett., 97, 195002, doi:10.1103/PhysRevLett.97.195002, 2006.

Henricson, H.: Results from the intercalibration of low light level sources at Andøya 2007, in: Proceedings of the 33rd Annual European Meeting on Atmospheric Studies by Optical Methods, edited by: Sandahl, I. and Arvelius, J., no. 292 in IRF Scientific report, p. 131, Swedish Institute of Space Physics, Kiruna, http://www.irf.se/publications/proc33AM, 2008.

Hunten, D. M., Roach, F. E., and Chamberlain, J. W.: A photometric unit for the aurora and airglow, J. Atmos. Terr. Phys., 8, 345-346, 1956.

Lauche, H. and Barke, W.: A calibration photometer for low brightness sources, in: Proceedings of the 13th annual Meeting on Upper Atmosphere Studies by Optical Methods, edited by: Måseide, K., University of Oslo, Department of Physics, 86-28, 364-370, 1986.

Lauche, H. and Widell, O.: Intercalibration of low light level sources, in: Proc. of 27th Annual European Meeting on Atmospheric Studies by Optical Methods, Stockholm, Sweden, Meteorological institution, Stockholm university, Sweden, 2000a.

Lauche, H. and Widell, O.: Intercalibration of low light level sources, Phys. Chem. Earth, B25, 483-483, 2000b.

Mäkinen, S.: All-sky camera calibration, Master's thesis, Helsinki University of Technology (now Aalto University), 2001.

Rayleigh, L.: Absolute Intensity of the Aurora Line in the Night Sky, and the number of Atomic Transitions Required to Maintain it, P. R. Soc. London, A129, 458-467, 1930.
Sigernes, F., Holmes, J. M., Dyrland, M., Lorentzen, D. A., Chernous, S. A., Svenøe, T., Moen, J., and Deehr, C. S.: Absolute calibration of optical devices with a small field of view, J. Opt. Technol., 74, 669-674, 2007.

Syrjäsuo, M. T.: Auroral monitoring network: From all-sky camera system to automated image analysis (D.Sc.(Tech.)-thesis), Finnish Meteorological Institute, Helsinki, Finland, Contribution series 32, ISBN: 951-697-551-8, 2001.

Torr, M. R.: Intercalibration of instrumentation used in the observation of atmospheric emissions: A progress report 1976-1979, Tech. Rep. 100, Utah State University, Center for atmospheric and space sciences, Logan Utah, 1981.

Torr, M. R.: Report on a project to intercalibrate instrumentation used in the observation of visible atmospheric emissions, Tech. rep., Utah State University, Center for atmospheric and space sciences, Logan Utah, 1983.

Torr, M. R. and Espy, P.: Intercalibration of instrumentation used in the observation of atmospheric emissions: Second progress report, Tech. Rep. 101, Utah State University, Center for atmospheric and space sciences, Logan Utah, 1981.

Torr, M. R., Hays, P. B., Kennedy, B. C., and Torr, D. G.: Photometer calibration error using extended standard sources, Appl. Optics, 15, 600-602, doi:10.1364/AO.15.000600, 1976.

Torr, M. R., Hays, P. B., Kennedy, B. C., and Walker, J. C. G.: Intercalibration of airglow observatories with the Atmosphere Explorer satellite, Planet Space Sci., 25, 173-184, 1977.

Trondsen, T. S.: High spatial and temporal resolution auroral imaging, Ph.D. thesis, University of Troms $\varnothing, 1998$.

Widell, O. and Henricson, H.: Intercalibration of low light level sources, in: Proc. of 28th Annual European Meeting on Atmospheric Studies by Optical Methods, 19-24.8.2001, Oulu, Finland, edited by: Kaila, K. U., Jussila, J. R. T., and Holma, H., Sodankylä Geophysical Observatory, 92, 125-125, 2003.

Widell, O. and Henricson, H.: Results from the intercalibration of low light level sources at IRF 2006, in: Proceedings of the 33rd Annual European Meeting on Atmospheric Studies by Optical Methods, edited by: Sandahl, I. and Arvelius, J., no. 292 in IRF Scientific report, Swedish Institute of Space Physics, Kiruna, p. 130, http://www.irf.se/publications/proc33AM, 2008.

Widell, O. and Mämmi, S.: Results from the intercalibration of low light level sources at Svalbard 2003, in: Proceedings of the 30th Annual European Meeting on Atmospheric Studies by Optical Methods, edited by: Sigernes, F. and Lorentzen, D., The University Centre on Svalbard, Longyearbyen, p. 121, 2003. 